ISSN: 0213-2079 - ISSN electrónico: 2386-3889

DOI: https://doi.org/10.14201/shhmo2018402177196

\title{
EL SABER MÉDICO DE LAS CURANDERAS NOVOHISPA- NAS: UN NICHO FEMENINO DENTRO DEL PLURALISMO MÉDICO DEL IMPERIO ESPAÑOL
}

\section{The Medical Knowledge of New Spain's "Curanderas»: A Feminine Niche in the Medical Pluralism of the Spanish Empire}

\section{Estela ROSELLÓ SOBERÓN}

Universidad Autónoma de México

Correo-e: estela.rosello@gmail.com

RESUMEN: Este artículo habla sobre el saber femenino de las curanderas novohispanas en el largo siglo XVII como un conocimiento que formó parte de la cultura médica del Imperio español en la época barroca. La hipótesis principal del trabajo es que este saber médico se construyó a partir de un complejo proceso de hibridación cultural que amalgamó en un solo corpus prácticas, métodos, terapias, medicinas, rituales, ideas y creencias sobre la salud, la enfermedad y el cuerpo humano procedentes de tradiciones indígenas americanas, prehispánicas, occidentales, africanas y en menor medida, asiáticas.

Fue precisamente este carácter híbrido el que hizo de este saber femenino un conocimiento con sentido y significado para hombres y mujeres de muy distintos orígenes culturales. La investigación parte del análisis de varios documentos inquisitoriales, más específicamente, denuncias y procesos contra algunas curanderas indias, españolas, africanas, mulatas y mestizas del virreinato americano. XVII.

Palabras clave: Curanderas; mujer y salud; tradiciones indígenas; siglo 
ABSTRACT: This article explores the knowledge produced and employed by New Spain's «curanderas» (women healers) in the course of the seventeenth century, as a form of knowledge that was part of the wider medical culture of the Spanish Empire during the baroque era. My central hypothesis suggests that curanderas' medical knowledge was built through a complex process of cultural hybridization which brought together into one corpus, the practices, methods, therapies, rituals, ideas, and beliefs about health, illness and the human body associated with different traditions of knowledge and praxis, including indigenous, pre-hispanic, Western, African, and to a lesser degree, Asian traditions.

It was precisely its hybrid character which made women's medical knowledge useful and meaningful to both men and women of varied cultural provenance. My research takes as its point of departure the analysis of several inquisitorial documents, specifically accusations and trials against indigenous, Spanish, African, mestizo and mulata women of the American viceroyalty of New Spain.

Key words: Women healers; medical knowledge; $17^{\text {th }}$ century; process of cultural hybridization.

\section{UN SABER INSCRITO EN UNA HISTORIA DE CONTACTOS E HIBRIDACIÓN CULTURAL}

La historiografía más reciente sobre la cultura del imperio español de los siglos XVI y XVII ha hecho énfasis en la historia de contactos. Procesos de conversión, circulación de objetos, personas, especies naturales, viajes trasatlánticos, intercambio de ideas, creencias y saberes; construcción de nuevas explicaciones e interpretaciones del mundo. Al final, el reto de encontrarse con «el otro», pero, sobre todo, de reconocerlo, de interactuar con él y, a partir de ello, de situarse en un lugar distinto y construirse a uno mismo de una manera diferente, propia.

Es ésa una historia que oscila, necesariamente, entre los diálogos y las imposiciones culturales; una historia, a veces, ciertamente de sometimiento, pero muchas otras, quizás la mayoría, una historia de mediación y negociación. Es allí, en esa dimensión de la historia de pactos, acuerdos y formas culturales de asimilación, intercambio y apropiación que se situó la historia de las curanderas novohispanas de los siglos XVI y XVII. Y es que, en su búsqueda de encontrar estrategias para vivir mejor en un mundo ordenado a partir de la supremacía de la autoridad masculina, estas mujeres se convirtieron en negociadoras por excelencia, y como parte de ello, se hicieron de un oficio y de una forma de vida caracterizados por la

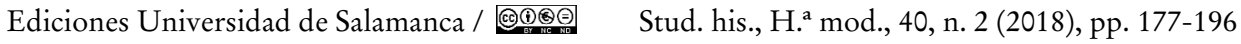


ESTELA ROSELLÓ SOBERÓN

EL SABER MÉDICO DE LAS CURANDERAS NOVOHISPANAS:

UN NICHO FEMENINO DENTRO DEL PLURALISMO MÉDICO DEL IMPERIO ESPAÑOL

articulación de muchas relaciones de contacto, intercambio e hibridación cultural propias de aquella sociedad virreinal diversa y plural ${ }^{1}$.

Es importante señalar que este proceso de hibridación no fue, de ninguna manera, un fenómeno que se diera de manera natural ni automática; por el contrario, se trató de un proceso en el que los intercambios y los préstamos generados por los contactos transformadores de los códigos culturales supusieron tensiones, luchas de poder, formas de jerarquización de saberes y un juego de equilibrios dinámicos y cambiantes.

Las curanderas de la Nueva España fueron mujeres de sectores sociales, orígenes y calidades muy distintos. La mulata Ana de Valencia, la media coyota Feliciana de la Garza, la loba Sebastiana, la mestiza María Cristina la Copete, la española Petrona de Fuentes o la filipina Martina son sólo algunas de las mujeres que se dedicaron a sanar enfermos a lo largo del siglo XVII en aquel virreinato americano español ${ }^{2}$. Ya en otros momentos se ha hablado de la importancia que estos sujetos históricos tuvieron como reguladores de conflictos sociales, como personas con autoridad dentro de sus comunidades y como mujeres con un prestigio particular. Efectivamente, entonces se insistió en el peso que tuvieron dichos personajes como intermediarios fundamentales en el orden cotidiano de sus comunidades ${ }^{3}$. Esta vez, lo que se quiere explorar a mayor profundidad es el lugar que tuvo el saber médico particular de las curanderas en la cultura médica del Imperio español del siglo XVII y, además, reflexionar sobre la relación que hubo entre la naturaleza

1, En este artículo retomo el concepto de hibridismo cultural desarrollado por Peter Burke. Durante muchas décadas, los historiadores y los antropólogos dedicados al estudio de la Nueva España y la cultura mexicana hablaron de mestizaje cultural para referirse al fenómeno de interacción, contacto o encuentro entre pueblos de tradiciones y orígenes muy distintos entre sí como fueron los españoles, los indígenas y los africanos. Hoy, resulta necesario encontrar otros conceptos que permitan comprender de manera más compleja la realidad plural del virreinato novohispano. El hibridismo cultural del que habla Burke puede resultar de gran utilidad en ese sentido. Burke, Peter: Hibridismo cultural.Madrid: Ediciones Akal, 2003.

2. Los nombres y las respectivas calidades de estas curanderas se encuentran registrados en diversos procesos de Inquisición del Archivo General de la Nación de México. Cabe señalar que los apelativos de «loba» y de «coyota» fueron nombres que se dieron a las personas que eran hijas de uniones mixtas entre indios, mulatos, negros y españoles. Por otro lado, los nombres de las curanderas aquí mencionadas se eligieron al azar, entre muchos otros, sólo para dar cuenta de la diversidad en el origen y la calidad de dichas mujeres.

3. Ver Roselló Soberón, Estela: Enfermar y curar. Historias cotidianas de cuerpos e identidades femeninas en la Nueva España. Valencia: Universitat de Valencia, 2017. Es importante señalar que las fuentes que utilizo para este artículo proceden de la investigación que realicé durante varios años y cuyos resultados se publicaron en el libro ahora citado. Si bien las fuentes y algunas ideas que se presentan a lo largo de estas páginas tendrán, evidentemente relación con aquello que se presentó en dicha investigación extensa, el propósito de este este artículo es hacer algunas reflexiones que no se hicieron entonces y que quedaron en el tintero.

Ediciones Universidad de Salamanca / 요 Stud. his., H. ${ }^{a}$ mod., 40, n. 2 (2018), pp. 177-196 
de dicho saber y la posibilidad de que estas mujeres fueran mediadoras culturales y sociales importantes en la cotidianidad de la Nueva España.

Son muchos los historiadores contemporáneos que han hablado de las experiencias de la búsqueda de la salud y la enfermedad como fenómenos culturales. Para ellos, estas experiencias humanas abrazan la construcción de una serie de representaciones sobre el cuerpo, un registro de emociones y sensaciones particulares, un conjunto de símbolos, ideas y creencias compartido, lo mismo que un sistema de prácticas, rituales, técnicas y saberes que las comunidades validan de manera constante en su cotidianidad $^{4}$. En ese sentido, las experiencias de la salud y la enfermedad reflejan, siempre, una interpretación o una traducción particular de la vida y del mundo ${ }^{5}$.

En realidad, en todas las sociedades y culturas, la manera en que los seres humanos se enfrentan con la enfermedad y buscan la curación o el alivio forman parte central de un sistema cognitivo complejo que describe la cosmovisión, el ethos y la manera de ordenar la existencia ${ }^{6}$. En el caso de la experiencia de la enfermedad y la búsqueda de la salud en la Nueva España, la medicina de las curanderas materializó la interpretación de un mundo híbrido particular. El uso de ciertas hierbas, la utilización de recursos mágicos procedentes de diversas tradiciones, la práctica de rezos y de rituales religiosos, la preparación de medicamentos, ungüentos, pócimas, aguas y pociones con recetas occidentales pero con ingredientes muchas veces locales formaron parte de un sistema de conocimiento cuyo fundamento era la creencia en la posibilidad de movilizar las fuerzas ocultas del cuerpo y de la naturaleza para conseguir resultados curativos eficaces para todos ${ }^{7}$. Fue precisamente en ese «para todos» que radicó el poder cotidiano de estas mujeres singulares.

4. Cabe recordar lo que dice Marshall Sahlins sobre cómo la cultura se reproduce históricamente en las acciones cotidianas de las personas. Para el antropólogo estadounidense, «la gente organiza sus proyectos y da significación a sus objetos a partir de los conocimientos existentes sobre la acción...». Sahlins, Marshall: Islas de historia. Barcelona: Gedisa, 2008, p. 9.

5. Entre muchos otros, el antropólogo mexicano Juan Gallardo ha señalado cómo «las creencias y actitudes que un pueblo determinado tiene acerca de la salud y la enfermedad reflejan sus formas de organización social, económica, familiar, su mundo religioso y cultural». Gallardo, Juan: Medicina tradicional purépecha. Zamora: EL Colegio de Michoacán/Universidad Indígena Intercultural de Michoacán, 2005, p. 14.

6. La explicación de las experiencias de la salud y la enfermedad como parte esencial de los sistemas cognitivos de las sociedades es de BenteGullveigAlver y TorunnSellberg. En su extraordinario artículo sobre medicina popular en Noruega, estos autores desarrollan las diferencias entre conceptos como cosmovisión, mundo conceptual y sistema cognitivo. Ver GullveigAlver, Bente y Selberg, Torunn: «Folk Medicine as Part of a Larger Concept Complex», Levack, Brian P. (ed.): New Perspectiveson Witchcraft, Magic and Demonology. Witchcraft, Healing and Popular Diseases. NY/London: Routledge, 2001, p. 22.

7. Entre los autores contemporáneos que también se ha ocupado de manera sugerente sobre el fenómeno de la relación entre todo este tipo de saberes y conocimientos y la manera

Ediciones Universidad de Salamanca / 
Efectivamente, la manera en que las curanderas novohispanas construyeron su saber médico obedeció a una forma compartida de ver la realidad, a un sistema cultural que incorporó elementos de tradiciones y orígenes muy diversos entre sí en una nueva mirada del mundo comprensible para muchos sujetos distintos, de allí la eficacia de sus remedios y curaciones. A diferencia del conocimiento más académico de los médicos universitarios, que abrevaba, sobre todo, de las teorías galénicas e hipocráticas occidentales, el saber de las curanderas de la Nueva España fue resultado de un proceso de hibridación cultural dinámico, cotidiano, en constante construcción ${ }^{8}$. Su naturaleza radicaba en ser parte de esas formas aprendidas de ver, pensar y experimentar la realidad en la vida diaria de una sociedad conformada por indios, españoles, mestizos, afrodescendientes y, si bien en mucho menor medida, también asiáticos?.

Ahora bien, como ya han señalado muchos estudiosos de la cultura médica de la Temprana Edad Moderna, y a diferencia de lo que suele creerse, entre los siglos XVI y XVII, no había una clara oposición entre la medicina «popular» y la medicina «científica» ${ }^{10}$. En realidad, los médicos universitarios y los demás profesionales de la salud de aquella época pudieron compartir un importante sustrato de ideas y creencias médicas comunes ${ }^{11}$.

en que se ha buscado la curación entre los sectores «populares» se encuentra Levack, Brian P.: Witchcraft, Healing and Popular Diseases. NY/London: Routledge, 2001.

8. Michael Stolberg ha señalado cómo diversos estudios sobre la cultura médica de la temprana Edad Moderna europea han mostrado la manera en que muchos médicos académicos aprendían de los conocimientos más empíricos y más populares de otros profesionistas de la salud. Ver Stolberg, Michael: «Learning from the Common Folks. Academic Physicians and Medical Lay Culture»: Social History of Medicine, vol. 27, Issue 4, Nov. 2014, p. 651. Efectivamente, de acuerdo con lo que se registra en muchos documentos de archivo del siglo XVII, muchos médicos novohispanos no sólo admiraron las formas de sanar de las curanderas, sino que incluso llegaron a invitar a dichas mujeres a trabajar con ellos en los hospitales donde ellos mismos practicaban. Sin embargo, no todos los médicos que estudiaban en la universidad eran tan flexibles ni tan abiertos.

9. OrvarLöfgren plantea que un sistema cognitivo es «una manera aprendida de ver, pensar y experimentar la realidad». Gullveig Alver, Bentey Selberg,Torunn: «Folk Medicine as Part of a Larger Concept Complex»,Levack, Brian P. (ed.): New Perspectives on Witchcraft, Magic and Demonology. Witchcraft, Healing and Popular Diseases. NY/London: Routledge, 2001, p. 23.

10. Carolin Schmitz y María Luz López Terrada han insistido en el error de pensar en una dicotomía entre la medicina académica y la medicina no académica en esta época. En su lugar, para explicar la cultura médica del barroco hispánico prefieren utilizar el concepto de pluralismo médico del que también han hablado otros historiadores, tales como José Pardo Tomás o Montserrat Cabré. Ver Schmitz, Carolin y López Terrada, María Luz. «Josep Rodriguez, herbolari valencià i els seus pacients de la ribera del Tajo. Les cultures mèdiques en el món rural barroc»: Afers82 (2015), p. 524.

11. Stolberg, Michael: «Learning from the Common Folks. Academic Physicians and Medical Lay Culture in the XVI Century»: Social History of Medicine, vol. 27, Issue 4, Nov. 2014, p. 649. 
ESTELA ROSELLÓ SOBERÓN

EL SABER MÉDICO DE LAS CURANDERAS NOVOHISPANAS:

UN NICHO FEMENINO DENTRO DEL PLURALISMO MÉDICO DEL IMPERIO ESPAÑOL

Sin embargo, para el caso de la Nueva España, si bien es cierto que muchos médicos universitarios adoptaron elementos locales en la práctica de su profesión, tales como el uso de ciertas hierbas originarias de la Nueva España y muchos de ellos admiraron el trabajo de algunas curanderas, en general, los doctores no tomaron tan en cuenta los saberes indígenas, africanos o asiáticos ni en sus diagnósticos, ni en sus interpretaciones sobre la salud y la enfermedad, ni mucho menos en el corpus de sus conocimientos teóricos. Por el contrario, el saber de las curanderas sólo cobró sentido y vida a partir de la integración de muchas tradiciones, incluida, por cierto, también, la galénica e hipocrática, en un saber nuevo y particular, propio sólo de dichas profesionales de la salud virreinal ${ }^{12}$.

\section{ESPECIALISTAS MUJERES DENTRO DE LA CULTURA MÉDICA NOVOHISPANA}

En la Nueva España, las curanderas tuvieron un campo de actuación muy amplio. Estas mujeres, a veces indígenas, a veces españolas, otras mulatas o mestizas, fueron llamadas lo mismo por hombres que por mujeres, lo mismo por gente de los sectores menos favorecidos que por personas de los estamentos privilegiados. El contacto y la interacción cotidiana con personas de procedencias y sectores tan diversos fue una condición fundamental en la construcción de su conocimiento y sus formas de curar, es decir, en la posibilidad de hacerse de un lugar propio en el universo del pluralismo médico de la Nueva España.

Ciertamente, las curanderas del virreinato americano no formaron gremio ni corporación que las identificara a partir de su quehacer médico; sin embargo, en la cotidianidad, en la vida diaria, la sociedad novohispana reconoció que las curanderas eran mujeres con una identidad particular. No sólo eso; además, la sociedad en general aceptó que el saber de las curanderas pertenecía sólo a ellas, y a nadie más. Se trataba, indiscutiblemente, de un saber femenino, y en ese sentido, de un saber misterioso, oculto, rodeado de un halo de magia y poder irracional ${ }^{13}$.

12. Una vez más es interesante pensar en lo que reflexionan Gullveig Alver y Selberg sobre los sistemas cognitivos de las sociedades como sistemas que expresan, de manera no implícita ni verbal, las reglas del juego de la cultura dentro de una sociedad. Ver Gullveig Alver y Selberg, Torunn: «Folk Medicine as Part of a Larger Concept Complex»,Levack, Brian P. (ed.): New Perspectives on Witchcraft, Magic and Demonology. Witchcraft, Healing and Popular Diseases. NY/London: Routledge, 2001, p. 23. En el caso de las curanderas de la Nueva España, su saber, como sistema cognitivo, era expresión, precisamente, de las reglas del juego de una realidad cultural diversa, plural.

13. En muchos de sus trabajos, María Tausiet ha advertido cómo en la cultura de la temprana Edad Moderna, heredera de la medieval, las mujeres eran tachadas de supersticiosas por definición. En consecuencia, y en palabras de la historiadora, «en el mundo científico [de aquella época] reinaba la convicción de que la práctica de la brujería demoníaca se relacionaba únicamente con

Ediciones Universidad de Salamanca / 요 Stud. his., H. ${ }^{a}$ mod., 40, n. 2 (2018), pp. 177-196 
Es decir, al tratarse de un atributo propio de mujeres, el saber de las curanderas estuvo, generalmente, en la mira y en el margen de lo que podía ser sospechoso, herético, pecaminoso y eso que podía aceptarse sin problema como ortodoxo y digno de admiración ${ }^{14}$. En cualquier caso, si el saber de las curanderas se veía como un conocimiento femenino y por lo tanto a veces peligroso, también es cierto que, su misterio y su particularidad, lo hacían poderoso.

En ese sentido, resultan curiosas las palabras y afirmaciones que el doctor Bartolomé González Parejo pronunciara en Puebla, en 1647, al delegar su responsabilidad médica en una mujer que él consideraba capaz de curar padecimientos que él era incapaz de sanar. La historia es más o menos ésta. Después de intentar curar de muchas maneras a doña María Sambrano, española, sin resultado alguno, el doctor González Parejo no tuvo más remedio que desahuciar a su paciente. No obstante, a pesar de su fatal diagnóstico, el doctor dejó abierta una leve esperanza para la enferma y su familia, ya que éste, al reconocer los límites de su conocimiento y pericia profesional, también señaló que «él no entendía aquella enfermedad» pero que «la cura [de aquel mal más parecía]de mujeres [que] de médicos» ${ }^{15}$.

Así, en esa sencilla declaración, el doctor González Parejo admitía que había ciertas cosas que sólo las curanderas podían curar, «achaques de mujeres», como los llamó, que correspondían más a cierto tipo de diagnóstico, conocimientos y prácticas terapéuticas que estaban fuera de su alcance.

Si bien en el siglo XVII el concepto de especialidad o especialización médica eran absolutamente inexistentes, había ciertos acuerdos tácitos que reconocían, entonces, linderos y asuntos distintos, para los cuales había profesionales de la salud diferentes. No hacían lo mismo los médicos que los cirujanos, ni los barberos que sabían practicar sangrías que los boticarios que conocían bien de recetas para

la naturaleza femenina, y por extensión, que toda mujer era bruja en potencia». Ver Tausiet, Martha: «Comadronas brujas en Aragón en la Edad Moderna: mito y realidad»: Revista d'historia moderna, n. 15, 1997, p. 381. En ese sentido, la práctica de las curanderas de la Nueva España siempre se vio como un qué hacer que tocaba las fronteras de la brujería y de lo diabólico.

14. Es también MartaTausiet quien señala el carácter maniqueo de la sociedad hispánica de la temprana Edad Moderna; una sociedad que autorizaba o prohibía aquello que consideraba pecaminoso o lícito. Por otro lado, Brian P. Levack explica cómo el acto de curar es, por definición, un acto benéfico. En ese sentido, las curanderas habrían sido vistas con buenos ojos por todos aquellos que las llamaban para pedirles ayuda. Sin embargo, tal como afirma también Tausiet, normalmente, las curanderas siempre fueron asociadas, en mayor o menor grado, con los poderes sobre naturales, con la magia, aun cuando se tratara de magia blanca, y no de brujería. Ver Levack, Brian, P. Witchcraft, Healing and Popular Diseases. NY/London: Routledge, 2001,p. VII. De allí que, en el caso de la Nueva España, la presencia y actuar de estos personajes femeninos fueran siempre vistos con recelo y cautela por parte de las autoridades inquisitoriales preocupadas por erradicar cualquier expresión mágica.

15. Inquisición, vol. 429, exp. 4, año 1647, f. 229-2230. 
ESTELA ROSELLÓ SOBERÓN

EL SABER MÉDICO DE LAS CURANDERAS NOVOHISPANAS:

UN NICHO FEMENINO DENTRO DEL PLURALISMO MÉDICO DEL IMPERIO ESPAÑOL

fabricar remedios y medicinas. Si bien las fronteras entre sus quehaceres no eran tan rígidas como las que podrían existir actualmente entre médicos especializados en detalles muy particulares de la salud humana, sí había un reconocimiento de áreas, procederes o prácticas médicas que correspondían a diferentes actores del pluralismo médico del siglo XVII ${ }^{16}$.

Es interesante pensar que, en el escenario cultural de la Nueva España, el saber médico de las curanderas incluyó la posibilidad de restablecer el equilibrio físico no sólo de los enfermos, sino, además, la posibilidad de sanar las relaciones sociales dañadas, rotas o negativas que, en la mentalidad popular del siglo XVII novohispano, frecuentemente se vinculaban con la causa de muchas enfermedades. Es decir, era habilidad propia de estas profesionistas recomponer el equilibrio de manera holística y así, recuperar no sólo la armonía en el cuerpo del enfermo, sino también, el equilibrio del orden social ${ }^{17}$. Esto, difícilmente habría sido materia de ningún otro médico universitario, boticario o cirujano de la Nueva España ${ }^{18}$.

Como en muchas otras latitudes del mundo de los siglos XVI y XVII, pero más aún, incluso de nuestro mundo contemporáneo, el fenómeno cotidiano en el que se intersectaron las enfermedades de las personas y el desequilibrio del orden social fue el hechizo. La creencia popular en la magia permeaba en las explicaciones sobre la manifestación de síntomas extraños en el cuerpo de las personas enfermas. Los hechizos, tal como puede observarse en muchos casos novohispanos, eran resultado de sentimientos como el enojo, los celos o la envidia, emociones que

16. Aquí es interesante recordar la definición que da Juan Gallardo para los especialistas de la medicina popular. De acuerdo con el antropólogo mexicano, las personas comunes y corrientes suelen reconocer a especialistas de la salud, es decir, a «personas que poseen habilidades médicas o terapéuticas particulares, y que aplican a determinados padecimientos, dentro del ejercicio de la medicina tradicional». Ver Gallardo, Juan: Medicina tradicional purépecha. Zamora: El Colegio de Michoacán/Universidad Indígena Intercultural de Michoacán, 2005, p. 43.

17. En su obra pionera y clásica sobre los curanderos de la Nueva España, Noemí Quezada sostenía que las curanderas daban seguridad tanto al enfermo, como a su familia y a su comunidad. Ver Quezada, Noemí: Enfermedad y maleficio. México: UNAM, 1989, p. 28. La antropóloga retomaba a Aguirre Beltrán quien en sus trabajos sobre magia y medicina en la Nueva España también señaló que el curandero tenía, entre otras, la función de mantener la seguridad dentro de su comunidad.

18. Vale la pena recordar que han sido los antropólogos los especialistas que han insistido en la función social que han tenido las curanderas a lo largo del tiempo. En sus trabajos clásicos, Malinowski, Levi Strauss o Marcel Mauss explicaron la relación entre las curaciones, muchas veces mágicas, y la recuperación del orden y el equilibrio social. En este sentido, Gullveig Alver y Selburg retoman el fenómeno del hechizo, fenómeno muy presente en la cotidianidad novohispana, que en muchas otras sociedades también se considera causa de muchas enfermedades. Ver Gullveig Alver y Selberg, Torunn: «Folk Medicine as Part of a Larger Concept Complex»,Levack, Brian P. (ed.): New Perspectives on Witchcraft, Magic and Demonology. Witchcraft, Healing and Popular Diseases. NY/London: Routledge, 2001, p. 28. 
ESTELA ROSELLÓ SOBERÓN

EL SABER MÉDICO DE LAS CURANDERAS NOVOHISPANAS:

UN NICHO FEMENINO DENTRO DEL PLURALISMO MÉDICO DEL IMPERIO ESPAÑOL

tenían funestos efectos en las relaciones sociales y en el funcionamiento pacífico del orden social. Las curanderas eran las especialistas médicas encargadas de dar solución a los males provocados por este tipo de fenómenos emocionales y mágicos. Además de curar a los enfermos de los síntomas provocados por los hechizos, estas profesionistas de la salud eran capaces de descubrir y revelar quiénes, cómo y por qué habían provocado de aquella manera, el mal, tanto físico como social.

\section{EL ORIGEN ANCESTRAL DEL OFICIO DE LAS CURANDERAS NOVOHISPANAS}

A lo largo del tiempo, y en muy distintas regiones del mundo, el oficio de sanar se ha vinculado con el universo femenino ${ }^{19}$. Dadas las características físicas y fisiológicas de su cuerpo, muchas culturas han considerado que las mujeres tienen un vínculo particular con lo sagrado, una habilidad especial para comprender los secretos de la naturaleza, así como una relación cercana con la dimensión de lo mágico ${ }^{20}$. En el caso de la sociedad novohispana, ésta también fue una creencia común. Más allá de que hubo curanderos hombres, los documentos hablan de una mayoría femenina dedicada al oficio de la medicina popular en la vida cotidiana del virreinato americano.

En tiempos prehispánicos, las sociedades mesoamericanas contaron con curanderos y curanderas que se dedicaban a asuntos médicos que discurrían en una realidad que no aceptaba separación tajante entre lo mágico y lo no mágico ${ }^{21}$. Los titici o curanderos eran hombres y mujeres reconocidos por tener poderes sobrenaturales, otorgados de manera predestinada. Independientemente de sus poderes mágicos o de los medios que utilizaranpara hacerlo, lo que era una verdad aceptada por todos era que los titicise dedicaban a curar enfermedades ${ }^{22}$.

Al llegar el siglo XVI y con él el contacto entre los curanderos prehispánicos y los conquistadores y autoridades españolas, los titici fueron considerados, de manera genérica, «hechiceros». Es decir, los primeros españoles que llegaron a los territorios de lo que sería la Nueva España, no tuvieron interés en hacer el matiz

19. Ya en algún momento, en Enfermar y curar, me referí a cómo siempre ha habido curanderos y curanderas, pero cómo la sanación se ha vinculado más a las mujeres que a los hombres. Ver Roselló Soberón, Estela: Enfermar y curar. Historias cotidianas de cuerpos e identidades femeninas en la Nueva España. Valencia: Universitat de Valencia, 2017, p. 55.

20. Roselló Soberón, Estela: Enfermar y curar. Historias cotidianas de cuerpos e identidades femeninas en la Nueva España. Valencia: Universitat de Valencia, 2017, p. 55.

21. López Austin, Alfredo: «Cuarenta clases de magos del mundo náhuatl» en Estudios de Cultura Nábuatl, 7, 1967. UNAM, p. 88.

22. López Austin, Alfredo: «Cuarenta clases de magos del mundo náhuatl» en Estudios de Cultura Nábuatl, 7, 1967. UNAM, p. 88. 
y distinguir entre los indígenas que eran médicos y aquellos que podían practicar como «brujos». Y es que, bajo la mirada occidental y cristiana de los españoles, los saberes autóctonos, las prácticas curativas, los procedimientos terapéuticos y el uso de ciertas hierbas alucinógenas de origen prehispánico sólo pudieron traducirse culturalmente como prácticas diabólicas. Efectivamente, en la nueva historia de contacto que supuso la conformación de la cultura y la sociedad virreinal, los saberes médicos prehispánicos se colocaron en los márgenes entre lo claramente demoniaco y lo sospechoso de serlo.

Como es fácil suponer, los saberes de muchas curanderas novohispanas incluyeron elementos de origen prehispánico que, en muchos casos, se calificaron como demoníacos. Esto, aunado a la naturaleza femenina de las sanadoras, favoreció que muchas de ellas fueran vistas con recelo y suspicacia por parte de las autoridades inquisitoriales y médicas occidentales. Ahora bien, al llegar el siglo XVII, las autoridades hispánicas intentaron distinguir con algo de mayor cuidado entre las curanderas o curanderos que realizaban su oficio a partir de procedimientos empíricos- si bien podían auxiliarse de la oración como medio ortodoxo para sanar-y aquéllos que lo hacían sólo mediante prácticas, rituales y saberes mágicos, supersticiosos y sobrenaturales ${ }^{23}$. Evidentemente, la posibilidad de hacer la diferencia entre ambos tipos de curandero o curandera fue siempre muy subjetiva y frágil ${ }^{24}$.

23. Más allá de la distinción entre un tipo de profesionista y otro, lo que sí era obvio para las autoridades hispánicas católicas es que, en cualquier caso, la enfermedad procedía de la voluntad divina. López Austin, Alfredo: «Cuarenta clases de magos del mundo náhuatl» en Estudios de Cultura Nábuatl, 7, 1967. UNAM, p. 108. Si bien los esfuerzos por clasificar y diferenciar bien a los buenos y malos médicos fueron más propios del siglo XVII, se sabe que, a mediados del siglo XVI, fray Bernardino de Sahagún ya hacía la distinción entre «el buen y el mal médico». Esto, tomando como referencia la sabiduría popular indígena, que consideraba que «El buen sabio, como buen médico, remedia bien las cosas, da buenos consejos y buena doctrina con que alumbra y guía a los demás... El mal sabio es mal médico, tonto, perdido, amigo del nombre de sabio y vanagloria, por ser necio causa de muchos males y grandes errores, peligroso, despeñador, engañador y embaucador». Ver Pardo Tomás, José: «Pluralismo médico y medicina de la conversión: fray Agustín Farfán y los agustinos en Nueva España (1533-1610)»: Hispania, 2014, V. LXXIV, n. 248 sept.-dic., p. 760. El historiador español toma la frase del libro X, capítulo 8, vol. 2 de la Historia de Sahagún.

24. El antropólogo e historiador Roberto Martínez señala que los curanderos eran perseguidos cuando su prestigio disminuía, a causa de algún paciente insatisfecho. Ver Martínez, Roberto: El nabualismo. México: UNAM, 2011, p. 374. Sin duda, esta condición se cumplió así en la realidad novohispana del siglo XVII. La información sobre el saber médico de las curanderas de la Nueva España que se presenta en las siguientes páginas procede de procesos y denuncias inquisitoriales contra mujeres que practicaron el oficio de curar y que fueron juzgadas por el Santo Oficio de México por ser consideradas supersticiosas, embusteras, hechiceras o aliadas del demonio. Todos los documentos están en el Archivo General de la Nación de México.

Ediciones Universidad de Salamanca / 
A partir del siglo XVI, las curanderas se habían hecho sentir en el escenario de la práctica médica virreinal y no habían tenido empacho en convivir e interactuar con los médicos españoles que hacían su labor en los primeros hospitales de los misioneros evangelizadores ${ }^{25}$. Por su parte, en un principio, no obstante, el reparo que tenían en torno a las prácticas prehispánicas consideradas diabólicas o cercanas a lo demoníaco, las autoridades virreinales no tuvieron más remedio que aceptar la presencia y el ejercicio médico de los curanderos y curanderas locales, que sabían muchas más cosas que ellos sobre enfermedades y remedios propios de las tierras recién conquistadas ${ }^{26}$.

De esta manera, las mujeres dedicadas al oficio de curar atendían partos, utilizaban sus conocimientos de la herbolaria local para fabricar medicinas y usaban técnicas y procedimientos de origen prehispánico para curar enfermos, ya fueran indios, españoles, mestizos, negros o mulatos.

Poco a poco y a lo largo del tiempo, todos los elementos de una cultura médica no sólo de origen prehispánico, sino también, empírica, se conservaron y se integraron en un nuevo saber que también incorporó conocimientos, creencias, ideas y prácticas europeas, africanas y posiblemente, en cierta medida, asiáticas. Ahora bien, en realidad, sería prácticamente inútil, y además ocioso, intentar desmenuzar la cultura médica de las curanderas para «descubrir» el origen cultural específico de todas sus prácticas, recetas medicinales o teorías. A decir verdad, es interesante pensar que muchas de ellas podrían haber procedido, simultáneamente, de tradiciones muy distintas en las que existían ideas o prácticas similares o análogas ${ }^{27}$. Por ello, más que saber si una práctica o un medicamento utilizado por estas mujeres era de origen prehispánico, europeo, africano o asiático, parecería que para el historiador lo verdaderamente importante sería reconstruir los métodos, terapias, medicinas y rituales utilizados por las curanderas de la Nueva España para comprender la conformación de una nueva expresión médica híbrida y femenina particular y propia de aquel virreinato, un saber que sin duda ocupó un nicho muy importante, no sólo dentro de la cultura médica novohispana, sino en la cultura médica de la temprana Edad Moderna del Imperio español en su conjunto. Veamos, pues, algunos ejemplos de cómo se expresó y manifestó el

25. Pardo Tomás, José: «Pluralismo médico y medicina de la conversión: fray Agustín Farfán y los agustinos en Nueva España (1533-1610)»: Hispania, 2014, V. LXXIV, n. 248 sept.-dic., p. 759.

26. Martínez, Roberto:«El poder de los curanderos en la antropolgía mexicanista. Una breve introducción»: Patricia Gallardo y Francois Lartigue. El poder de saber. Especialistas rituales de México y Guatemala. México: UNAM, 2014, p. 16.

27. Aquí merece la pena recordar lo que explica Peter Burke sobre la manera en que las tradiciones se transforman a partir de su interacción cotidiana; como consecuencia de dicho proceso, es frecuente que surjan entre ellas afinidades y convergencias. Ver Burke, Peter. Hibridismo cultural. Madrid: Ediciones Akal, 2003, p. 86.

Ediciones Universidad de Salamanca / 요 Stud. his., H. ${ }^{a}$ mod., 40, n. 2 (2018), pp. 177-196 
ESTELA ROSELLÓ SOBERÓN

EL SABER MÉDICO DE LAS CURANDERAS NOVOHISPANAS:

UN NICHO FEMENINO DENTRO DEL PLURALISMO MÉDICO DEL IMPERIO ESPAÑOL

hibridismo de aquella cultura médica curanderil femenina y novohispana en el largo siglo XVII.

\section{DE PURGAS Y EXTRACCIÓN DE MATERIA DAÑINA}

Entre los procedimientos terapéuticos más socorridos entre las curanderas de la Nueva España se encontraron las purgas y técnicas para extraer objetos extraños del cuerpo de los enfermos. Efectivamente, entre dichas mujeres, una de las formas más comunes para curar a sus pacientes fue recurrir a diferentes medicamentos y rituales que provocaban la expulsión de objetos y materia contaminante para el cuerpo. La manera de provocar que las personas echaran fuera aquello que les hacía daño podía variar mucho; lo curioso es que, en muchos casos, los objetos contaminantes que salían tras la purga eran más o menos siempre los mismos.

Agustina de Lara, por ejemplo, curandera española o mestiza que trabajaba en la ciudad de México hacia 1709 solía curar de hechizo a sus pacientes «sacándoles arañas y gusanos» del cuerpo ${ }^{28}$. Algo parecido hacía Micaela de Ybarra, curandera de Guadalajara que practicaba hacia 1686 en aquella ciudad. Cuentan los documentos que, alguna vez, Micaela asistió a la casa de Juana, una niña mala de la pierna, a quien la curandera le sacó por la boca varios gusanos peludos ${ }^{29}$. Otra mulata vieja, llamada Beatriz y apodada la Piatzin, curaba en la hacienda de Tlahuapan, en 1716, sacando escarabajos del ombligo a sus enfermos. En alguna ocasión, la Piatzin curó a una mujer de nombre Lucía, a quien le sacó de la pierna «muchas piedrecillas menudas que llaman tepecile y pelos de puerco» ${ }^{30}$.

Siguiendo el principio de sacar del cuerpo aquello que enfermaba, algunas otras curanderas de la Nueva España proporcionaban a sus clientes minorativas para evacuar y curar el organismo con ello. Como bien se sabe, las purgas fueron uno de los procedimientos más importantes de la medicina galénica ${ }^{31}$. Sin embargo, al mismo tiempo, se sabe que, en tiempos prehispánicos, extraer objetos extraños del cuerpo de los enfermos también fue una práctica terapéutica común. Así, el tetlacuicuiliqui era «el que saca algo de la gente». Este tipo de médico solía masticar estafiate, una planta medicinal local que siguió utilizándose mucho en

28. AGN, Inquisicón, Vol. 765, Exp. 10, Año 1709, f.145-145v.

29. AGN, Inquisición, Vol. 1551, Exp. 25-26, año 1686, f. 349.

30. AGN, Inquisición, Vol. 1051, s/exp., f. 168v.

31. Pardo Tomás, José: «Pluralismo médico y medicina de la conversión: fray Agustín Farfán y los agustinos en Nueva España (1533-1610)»: Hispania, 2014, V. LXXIV, n. 248 sept.-dic., p. 754. En realidad, las purgas obedecían a la idea occidental de purificar el interior del cuerpo con vómitos o evacuaciones que limpiaban a las personas. Alain Corbin desarrolla la historia de la importancia que tuvo la noción de higiene en las prácticas médicas medievales y renacentistas europeas. Ver Corbin, Alain: Historia del cuerpo. Madrid: Taurus, 2005, p. 23.

Ediciones Universidad de Salamanca / 요 Stud. his., H. ${ }^{a}$ mod., 40, n. 2 (2018), pp. 177-196 
tiempos coloniales, y con el que los curanderos rociaban y frotaban a sus enfermos. Después de hacerlo, los palpaban en las partes que les dolían y les sacaban «papel, obsidiana, pedernal, trozos de madera, unas piedras llamadas azcaxalli y otras pequeñas, que eran las enfermedades materializadas ${ }^{32}$.

Es interesante pensar que, hacia fines del siglo XVI, en la ciudad de Bengen, Noruega, dos mujeres presenciaron la curación que una hechicera practicó a otra mujer de nombre Tollichenn, en la que la sanadora hizo que esta última vomitara en un recipiente «objetos raros, tales como cerdas de cochino y cosas así» ${ }^{33}$.

Como es fácil advertir, la coincidencia entre el principio purificador de las prácticas médicas prehispánicas que pudieron perdurar en el tiempo en la cultura de las curanderas virreinales y las prácticas médicas europeas de la temprana Edad Moderna, que también pudieron llegar a dichas mujeres novohispanas, vía la tradición hispánica, es evidente. Es obvio que meterse en el galimatías de averiguar si la práctica de la extracción de cosas del cuerpo que llevaban a cabo las curanderas de la Nueva España tenía un origen prehispánico o uno europeo, parecería más bien ocioso. En cambio, seguramente resultaría mucho más fructífero explicar la manera en que las curanderas mestizas, españolas, indias y mulatas de la Nueva España del largo siglo XVII incorporaron ideas, creencias e imaginarios de tradiciones muy diversas para construir su propio saber y ejercer su oficio de una manera particular en una sociedad plural y diversa como fue la virreinal.

\section{TOCAR, UNTAR, CORTAR Y PUNZAR}

En la tradición médica occidental, curar mediante el tacto fue una práctica que se remontaba, por lo menos, a tiempos de $\mathrm{Cristo}^{34}$. $\mathrm{Al}$ mismo tiempo, dentro de la medicina prehispánica, el poder de tocar también se reconoció como un procedimiento eficaz para curar enfermos desde tiempos muy remotos. Vale la pena recordar que, en el caso de la tradición indígena, hubo muchas variantes de

32. López Austin, Alfredo: «Cuarenta clases de magos del mundo náhuatl» en Estudios de Cultura Nábuatl, 7, 1967. UNAM, p. 110.

33. Bente Gullveig y Selbergson quienes recuperan este pasaje de algún proceso judicial en contra de dicha bruja noruega. Gullveig Alver y Selberg, Torunn: «Folk Medicine as Part of a Larger Concept Complex»,Levack, Brian P. (ed.): New Perspectives on Witchcraft, Magic and Demonology. Witchcraft, Healing and Popular Diseases. NY/London: Routledge, 2001, p. 27.

34. La obra clásica para la historia de la curación táctil milagrosa es, obviamente, la de Marc Bloch, Los reyes taumaturgos. En su investigación sobre las curaciones milagrosas practicadas por los reyes taumaturgos, Bloch explora cómo el poder de los reyes franceses procedía de un bálsamo de óleo milagroso, el bálsamo de Clodoveo, con el que se ungía a los monarcas medievales. Ver Bloch, Marc: Los reyes taumaturgos. México: FCE, 2006, p. 213. Como se verá más adelante, en la cultura médica novohispana, heredera de la tradición médica occidental, la utilización de ungüentos y óleos para untar y curar fue práctica muy común entre las curanderas.

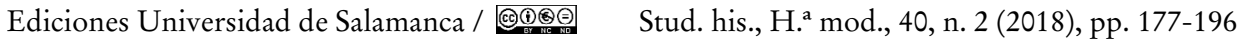


curaciones táctiles. Como es fácil observar en algunos documentos coloniales, parecería que muchas de ellas perduraron a lo largo del tiempo y aparecieron, ya transformadas y enriquecidas con otros elementos, en la práctica médica de las curanderas del virreinato novohispano.

Se sabe por ejemplo que, en el mundo prehispánico, una técnica curativa consistió en pisar a los enfermos. Este procedimiento terapéutico requería que el médico en cuestión tuviera callos gruesos en los pies, ya que éste debía colocar sus plantas sobre un comal o una piedra muy caliente, antes de proceder a realizar la terapia curativa. Una vez que el médico percibía el dolor propio del exceso de calor en los pies, entonces, éste pisaba en la espalda a su paciente, quien debía ponerse de bruces y escuchar las fórmulas mágicas que también acompañaban al procedimiento médico ${ }^{35}$.

En 1729, en el Real de Minas de Sultepec, la curandera española Francisca de Avilés visitó a doña Antonia, otra mujer, también española, que se encontraba muy enferma de «mal de madre». Lista para empezar la curación de su paciente, Francisca se quitó los zapatos, se sacudió los pies, encendió una vela al revés, rodeó a la enferma «y brincó encima de su cuerpo en la cama». Mientras lo hacía, la curandera «hablaba palabras que no se le entendían y tocaba el estómago [de su paciente] diciendo que allí tenía el daño». Cuando Francisca tocaba el estómago de doña Antonia, se abría en él «un hueco en que cabría un puño». Una vez que terminó con los procedimientos táctiles de su tratamiento, la curandera suministró a la enferma «un agua» que ella misma confeccionó con canela, azúcar y clavos. Al dársela a doña Antonia, Francisca señaló que «con ella sanaría si fuera hidropesía».

Como puede observarse, en este caso de curación, la práctica prehispánica de pisar a la enferma se complementó con los saberes clásicos de la medicina europea hipocrática-galénica. Más todavía: para preparar la pócima, Francisca usó «unas bulas viejas, dos velas de cebo y un poco de agua bendita» ${ }^{36}$. En realidad, lo más interesante de este ejemplo es que no podemos saber a ciencia cierta si, en tiempos anteriores a la conquista, la terapia médica de aparente origen prehispánico, que la curandera española usó, se hubiese utilizado para curar, precisamente «el mal de madre», esa enfermedad que la curandera diagnosticó a su paciente en tiempos virreinales con un nombre de enfermedad absolutamente occidental. Es decir, no podemos saber si dicho procedimiento terapéutico habría tenido, al menos en este caso, algún efecto fisiológico real para curar ese mal. Pero en realidad, no es eso lo verdaderamente importante. Para el historiador, lo que sí llama la atención es el hecho de que la curandera española había aprendido, escuchado, visto o imitado

35. López Austin, Alfredo: «Cuarenta clases de magos del mundo náhuatl» en Estudios de Cultura Nábuatl, 7, 1967. UNAM, p. 111.

36. AGN, Inquisición, vol. 826, exp. 43, año 1729, f. 433-438v. 
aquel ritual médico de origen prehispánico y lo había incorporado en su práctica cotidiana como uno más de los saberes y destrezas útiles para ejercer su oficio de manera más completa. Veamos otros ejemplos de hibridismo cultural.

En la medicina occidental, la utilización de óleos y ungüentos para curar a los enfermos fue práctica común. En el caso de las curanderas de la Nueva España, muchas de ellas acostumbraron a sobar y refregar el cuerpo de sus pacientes con óleos y unturas preparadas por ellas mismas. En muchos casos, es curioso advertir la presencia de ingredientes que se mencionan en las recetas médicas de la tradición galénica e hipocrática occidental de la Edad Media y del Renacimiento. Se sabe que las curanderas de la Nueva España surtían sus recetas en mercados y en boticas, lugares donde podían encontrar los ingredientes recomendados por la medicina occidental.

Así, por ejemplo, cuando la mulata Manuela Josepha diagnosticó a su paciente con «sangre lubia», para curarla, ésta «le aplicó unas claras de huevo con polvos de rosa en las espaldas y en el vientre yemas de huevo con aceite rosado, que le dio tres pócimas en tres días de aceites y tres minorativas al modo de purgas compuestas y cañafístula» ${ }^{37}$. La combinación de las unturas con las purgas habría resultado, de acuerdo con la curandera, un remedio por demás eficaz.

Otro caso. Cuando Micaela de Ybarra trató a la niña Juana del mal de su pierna en Guadalajara, la curandera preparó varios emplastos para aplicarlos sobre la piel de su paciente. Así, una mañana, la mestiza «pidió unos huevos y una cazuela nueva y una candela de sebo derretido y todo hizo un emplasto a modo de una torta en la cazuela y con ella envolvió la pierna...». Otro día, la mestiza «trujo unos quelites metidos en sebo o manteca» y preparó con ellos otro emplasto; después de envolver la pierna de la niña con él, Micaela pidió a su madre que "comprase una candela grande de a medio y la encendiese a la Virgen Santísima de la Soledad para que le hiciese compañía a su hija» en el período del tratamiento ${ }^{38}$.

Efectivamente, la presencia de imágenes de santos, santas, vírgenes y cristos milagrosos fue otro elemento común en la práctica médica de las curanderas de la Nueva España. Y es que, como en toda sociedad contrarreformista hispánica, en el virreinato americano, las experiencias de la salud y de la enfermedad estuvieron muy vinculadas con las creencias y la experiencia religiosa católica ${ }^{39}$.

37. AGN, Inqusición, vol. Exp. 6, año 1752.

38. AGN, Inquisición, vol, 1551, tomo 2, exp. 25-26, año 1686, f. 355v. Es interesante ver cómo la preparación del emplasto incluía ingredientes de origen europeo, como era la manteca de cerdo, y americano, como eran los quelites, una planta local muy típica de ciertas regiones de la Nueva España.

39. Ver López Terrada, María Luz: «Curanderos, empíricos y remedios mágicos en el teatro del Siglo de Oro» en José Pardo Tomás y Mauricio Sánchez Menchero (eds.). Geografías médicas. Orillas y fronteras culturales de la medicina (siglos XVI y XVII). México: CEICH/ UNAM, 2014, p. 22. 
Ahora bien, si las sangrías habían sido uno de los procedimientos fundamentales de la medicina occidental medieval y renacentista, en el caso de los saberes médicos prehispánicos, también había habido algunas prácticas similares que al llegar los siglos XVI y XVII, se resignificaron culturalmente y formaron parte de las prácticas médicas de las curanderas novohispanas. Aquí, merece la pena señalar un ejemplo típico de cómo pudieron funcionar las tensiones culturales en la conformación de algunas prácticas médicas híbridas de las curanderas en la Nueva España. Es bien conocida la importancia que tuvieron las punciones y las sangrías en la medicina galénica occidental. $\mathrm{Al}$ mismo tiempo, es bien conocido que, en el México prehispánico, la práctica de las punciones sacrificiales y religiosas fue cosa de todos los días. Cuando los médicos españoles llegaron al Nuevo Mundo y quisieron poner en práctica las terapias de la punción, éstos se encontraron con que los pueblos prehispánicos ya practicaban aquel procedimiento, pero no siempre con fines médicos, sino más bien, religiosos y bajo la mirada católica hispánica, con claros objetivos idolátricos. Evidentemente, las autoridades españolas prohibieron continuar con la práctica de punzar el cuerpo cuando ésta tuviera fines contrarios a la fe católica y al dogma cristiano; sin embargo, en el campo médico, la ejecución de punciones con fines galénicos-es decir, recuperar el equilibrio de los humores en el cuerpo, fue permitida y aceptada. Las curanderas de la Nueva España ejecutaron curaciones de este tipo de manera cotidiana. Como en muchos otros casos, no podemos saber con absoluta certeza cuál era el verdadero significado que estaba detrás de dicho procedimiento terapéutico. En principio se podría suponer que se sustentaba en la circulación popular de conocimientos de la medicina occidental, si bien no es imposible que en algunas punciones médicas, pudieran haber quedado vestigios de antiguas creencias religiosas prehispánicas.

Por otro lado, y para profundizar en el fenómeno en que las terapias híbridas, cercanas a la punción del cuerpo, es bien sabido que algunos curanderos indígenas de la época anterior a la llegada de los españoles solían dibujar «con unas navajuelas unos círculos culebreados como si estuviera una culebra enroscada en la cabeza» del enfermo. Esta práctica de sanación la podían practicar lo mismo curanderos hombres que curanderas mujeres ${ }^{40}$. Por otro lado, en tiempos prehispánicos, se sabe que los médicos también acostumbraban a punzar a los enfermos para curarlos de diferentes padecimientos.

Una vez más, merece recordar el caso de las curaciones que Micaela de Ybarra practicara sobre la pierna de la niña Juana en Guadalajara en 1686. Después de un

40. López Austin, Alfredo: «Cuarenta clases de magos del mundo náhuatl» en Estudios de Cultura Nábuatl, 7, 1967. UNAM, p. 110. López Austin hace hincapié en cómo, a diferencia de las sangrías que sólo las podían practicar médicos hombres, este tipo de cortaduras podían ser efectuadas por mujeres curanderas, también.

Ediciones Universidad de Salamanca / 요 Stud. his., H. ${ }^{a}$ mod., 40, n. 2 (2018), pp. 177-196 
largo proceso que no arrojaba los resultados deseados, Micaela decidió hacer a su paciente «unas cortaduras que parecía le habían sajado con cuchillo y agujeros y luego le puso un emplasto y se la envolvió». Por si fuera poco, la curandera «picaba la pierna con un alfiler grande dorado que traía en el paño de su cabeza y con una pluma de gallina... luego le ponía unos polvos y otros más de solimán labrado...» porque, de acuerdo con la experta, lo que ocurría con Juana era que «le había quedado el mal humor solapado ${ }^{41}$.

Es éste un ejemplo muy claro de cómo se habría manifestado el hibridismo cultural del saber médico de las curanderas novohispanas. Las antiguas prácticas prehispánicas de cortar y punzar que habían sobrevivido a veces de manera consciente, otras, de manera latente o recesiva, se activaban en la práctica médica de Micaela, quien no sólo recurría a ellas, sino que, de manera similar a lo que se obtenía con las sangrías occidentales, las usaba para curar padecimientos diagnosticados a partir de términos galénicos e hipocráticos como era el remediar el humor que se había quedado solapado en la pierna de la pobre niña Juana. Eso, sin contar, por supuesto, la utilización del solimán labrado, tan común en la medicina hispánica del siglo XVI.

\section{LIMPIAR Y SAHUMAR: LAS HIERBAS MEDICINALES}

Frecuentemente, las curanderas de la Nueva España recomendaban limpiar y sahumar a sus pacientes para devolverles el equilibrio y la salud corporal. Este tipo de procedimientos médicos se realizaba a partir de la utilización de diferentes plantas y hierbas locales cuyo uso medicinal perduró en la tradición médica colonial, no obstante, la cautela con la que muchos médicos españoles aceptaron usarlas ${ }^{42}$.

Entre las hierbas locales más utilizadas por las curanderas de la Nueva España se encontraron elestafiate y el tabaco ${ }^{43}$. Ambas especies eran valoradas por sus propiedades narcóticas y curativas. Así, por ejemplo, en 1730, en un poblado cerca

41. AGN, Inquisición, vol. 1551, tomo 2, exp. 25-26, año 1686, f. 356.

42. José Pardo Tomás ha señalado la desconfianza que experimentaron muchos frailes que conocieron las destrezas de los herbolarios indígenas. Para los frailes, parecía evidente que los curanderos indios que usaban aquellas especies invocaban poderes sobrenaturales relacionados con dichas plantas, lo cual se veía como una práctica peligrosa y ciertamente nada virtuosa. Sin embargo, dadas las necesidades médicas reales, los frailes sucumbieron y aceptaron utilizar algunas de las hierbas curativas recomendadas por los expertos indígenas. Pardo Tomás, José. «Pluralismo médico y medicina de la conversión: fray Agustín Farfán y los agustinos en Nueva España (1533-1610)» en Hispania, 2014, V. LXXIV, n. 248 sept.-dic. P. 749-776, p. 760.

43. En su obra clásica sobre la enfermedad en la Nueva España, Noemí Quezada explica que el tabaco y el estafiate fueron plantas muy socorridas por las curanderas que las usaban para hacer friegas, limpias, emplastos e infusiones. Ver Quezada, Noemí. Enfermedad y maleficio. México: UNAM, 1989, p. 59. 
del ojo de agua de Tepetatillo, en Aguascalientes, la mulata libre Ana de Estrada llamó a la curandera coyota Feliciana para que le ayudara a curarse. La experta en remedios médicos asistió a ver a su paciente «y le hizo algunos remedios, limpiándola con estafiate y copal, encendiendo velas delante de un altar que tenía en su casa, sacándole cerdas prietas y arenas y espinas de nopal...» ${ }^{44}$.

En el caso de la curandera mulata Beatriz, alias la Piatzin, ésta curó a Lucía, una india viuda en 1716 vivía en el pueblo de San Salvador y quien estaba enferma de «unos granos que tenía en el empeine y la cintura». Para sanarla, la Piatzin la refregó con estafiate y también le apretó las partes del cuerpo afectadas con otras hierbas ${ }^{45}$.

\section{ALGUNAS CONSIDERACIONES PARA REFLEXIONAR}

El saber médico de las curanderas de la Nueva España en el siglo XVII abrevó de fuentes y tradiciones muy distintas. Muchas de estas mujeres aseguraban haber aprendido lo que sabían con médicos con los que habían convivido, otras estaban convencidas de haber sido predestinadas con el don de la curación o de haber recibido su conocimiento por revelación divina. Muchas más guardaban silencio sobre la procedencia de su conocimiento, pero éste se había ido conformando no sólo a lo largo de su propia vida, sino atravesando el paso del tiempo, perdurando de generación en generación. $Y$ es que muchas curanderas del virreinato americano aprendían de sus congéneres todos los días; la circulación de información entre mujeres indias, mulatas, mestizas o españolas dedicadas a curar y que hablaban o se observaban entre sí fue cosa de todos los días. Además, estas mujeres sanadoras incorporaban en su saber todo aquello que ellas mismas iban aprendiendo de manera empírica en su práctica diaria. No sólo eso. La convivencia cotidiana con pacientes de orígenes y procedencias muy diversos también contribuyó en la conformación de un saber que integró en un nuevo sistema cognitivo, útil para interpretar la salud y la enfermedad de una manera particular, nombres de enfermedades, diagnósticos, recetas de pócimas, aguas y ungüentos, procedimientos terapéuticos y rituales religiosos de tradiciones muy diferentes entre sí.

El saber médico de estas mujeres fue una de las voces femeninas dentro del pluralismo médico del Imperio español del siglo XVII. Fue ése un universo cultural de saberes y conocimientos diversos sobre el cuerpo, sobre la salud, sobre la enfermedad y que, al coexistir, a veces compitieron, otras se confrontaron, muchas veces entraron en conflicto y otras más, negociaron y dieron origen a expresiones

44. AGN, Inquisición, vol. 830, exp. 11, año de 1730, f. 151.

45. AGN, Inquisición, vol. 1051, s/exp., f. 174.

Ediciones Universidad de Salamanca / 요 Stud. his., H. ${ }^{a}$ mod., 40, n. 2 (2018), pp. 177-196 
médicas híbridas propias de un mundo de contactos, intercambios y encuentros culturales intensos y cotidianos ${ }^{46}$.

En la Nueva España, la cultura médica híbrida de las curanderas fue traducción del orden cultural complejo y diverso de la sociedad virreinal. En su quehacer profesional, estas especialistas no abandonaron ninguna tradición médica, sino más bien, las resignificaron todas para integrarlas en ese nuevo saber femenino poderoso, contenedor, vivo, dinámico y abierto que se construía de manera cotidiana, en la práctica y en la acción. Seguramente, la apropiación de elementos médicos de tradiciones diversas entre sí se hizo de manera selectiva; en su día a día, las curanderas tuvieron que elegir entre aquellos saberes que les resultaban más útiles y eficaces para ejercer su profesión. Sin embargo, probablemente lo más interesante de aquel fenómeno de apropiación selectiva es que aquello que las curanderas eligieron como lo más útil para incorporar a su saber profesional no fue, necesariamente, lo que nosotros pudiéramos juzgar hoy como más eficaz en términos biomédicos o fisiológicos. Sí, en cambio, habría sido lo más eficiente para articular un diálogo con los pacientes con los que había que negociar e interactuar de manera cotidiana en la realidad cultural del siglo XVII novohispano. Es decir, la elección de saberes, prácticas, medicinas, terapias, diagnósticos, nombres de enfermedades que las curanderas hacían en su quehacer diario se realizaba, de manera consciente o inconsciente, a partir de aquello que estas profesionistas de la salud se daban cuenta que sus pacientes podían comprender, aceptar o sentir como propio. A partir de aquello que, de alguna manera u otra, formaba parte del sentido común de esa sociedad. Efectivamente, el saber médico de las curanderas novohispanas era polifónico; la multiplicidad de voces que resonaban en él daba origen a un saber que no era producto de una «mezcla» homogénea de culturas puras, sino un saber que resultaba de múltiples voces culturales que sonaban al mismo tiempo, en tonos distintos ${ }^{47}$. Habría sido precisamente este carácter híbrido y polifónico lo que hizo de aquel saber una explicación de la salud y la enfermedad comunicable y comprensible para la mayor parte de los habitantes de la Nueva España y, por lo tanto, lo que hizo de él una interpretación de la realidad culturalmente eficaz.

46. Slater, LópezTerrada, Pardo Tomás. Medical Cultures of the Early Modern Spanish Empire, NY/London: Routledge, 2016.s.p.

47. La idea de la polifonía como elemento central en el fenómeno del hibridismo cultural es de Peter Burke. Ver Burke, Peter. Hibridismo cultural. Madrid: Ediciones Akal, 2003,p. 97. 
ESTELA ROSELLÓ SOBERÓN

EL SABER MÉDICO DE LAS CURANDERAS NOVOHISPANAS:

UN NICHO FEMENINO DENTRO DEL PLURALISMO MÉDICO DEL IMPERIO ESPAÑOL

\section{BIBLIOGRAFÍA CONSULTADA}

Bloch, Marc: Los reyes taumaturgos: estudio sobre el carácter sobrenatural atribuido al poder real particularmente en Francia e Inglaterra. México: FCE, 2006.

Burke, Peter: Hibridismo cultural. Madrid: Ediciones Akal, 2003.

Corbin, Alain y Georges Vigarello: Historia del cuerpo. V. II, Madrid: Taurus, 2005.

Gallardo, Juan: Medicina tradicional p'urbepecha. Zamora: EL Colegio de Michoacán/ Universidad Indígena Intercultural de Michoacán, 2005.

Gullveig Alver, Bente y Torunn Selberg: «Folk Medicine as Part of a Larger Concept Comple x» en Brian P. Levack (ed.). New Perspectives on Witchcraft, Magic and Demonology. Witchcraft, Healing and Popular Diseases. NY/London: Routledge, 2001.

Levack, Brian P.: «Introduction»: Brian P. Levack (ed.). New Perspectives on Witchcraft, Magic and Demonology. Witchcraft, Healing and Popular Diseases. NY/London: Routledge, 2001.

López Austin, Alfredo: «Cuarenta clases de magos del mundo náhuatl» en Estudios de Cultura Nábuatl, 7, 1967. UNAM.

López Terrada María Luz: «Curanderos, empíricos y remedios mágicos en el teatro del Siglo de Oro» en José Pardo Tomás y Mauricio Sánchez Menchero (eds.). Geografías médicas. Orillas y fronteras culturales de la medicina (siglos XVI y XVII). México: CEICH/UNAM, 2014.

Martínez, Roberto: «El poder de los curanderos en la antropología mexicanista. Una breve introducción» en Patricia Gallardo y Francois Lartigue. El poder de saber. Especialistas rituales de México y Guatemala. México: UNAM, 2014.

Martínez, Roberto: El nabualismo. México: UNAM, 2011.

Pardo Tomás, José: «Pluralismo médico y medicina de la conversión: fray Agustín Farfán y los agustinos en Nueva España (1533-1610)» en Hispania, 2014, V. LXXIV, n. 248 sept.-dic., p. 749-776.

Quezada, Noemí: Enfermedad y maleficio. México: UNAM, 1989.

Roselló Soberón, Estela: Enfermar y curar. Historias cotidianas de cuerpos e identidades femeninas en la Nueva España. Valencia: Universitat de Valencia, 2017.

Sahlins, Marshall: Islas de historia. La muerte del capitán Cook. Metáfora, antropología e historia. Barcelona: Gedisa, 2008.

Schmitz, Carolin y María Luz López Terrada: «Josep Rodriguez, herbolari valencià i els seus pacients de la ribera del Tajo. Les cultures mèdiques en el món rural barroc»:Afers 82 (2015), p. 523-550.

Slater, John, María Luz López Terrada y José Pardo Tomás (eds.):Medical Cultures of the Early Modern Spanish Empire. NY/London: Routledge, 2016.

Stolberg, Michael: «Learning from the Common Folks. Academic Physicians and Medical Lay Culture in the Sixteenth Century» en Social History of Medicine, vol. 27, Issue 4, Nov., 2014, p. 649-667.

Tausiet, María: «Comadronas-brujas en Aragón en la Edad Moderna: mito y realidad» en Revista d'historia moderna, n. 15, 1997, p. 377-392. 